\title{
Detection of Stator Winding Short Circuit Faults Through Magnetic Fields In Induction Motors
}

\section{Deteksi Gangguan Hubung Singkat Belitan Stator Melalui Medan Magnet Di Motor Induksi}

\author{
Bima Rachmat Ah Ro Ufun"), Iradiratu Diah Prahmana Karyatanti'), Belly Yan Dewantara ${ }^{3)}$ \\ ${ }^{1,2,3)}$ Electrical Engineering, Hang Tuah University Surabaya, Indonesia \\ 1)Bimarachmat81@gmail.com ${ }^{2)}$ iradiratu@hangtuah.ac.id \\ 3) bellyyandewantara@yahoo.com
}

\begin{abstract}
In applications in the industrial world, the use of induction motors has been widely used in operation because induction motors have many advantages, although they have many advantages, induction motors themselves also have disadvantages, namely having high starting currents. In many cases the damage to the induction motor, the damage to the stator due to a short circuit, is a frequent failure, this damage can cause considerable losses because the motor can stop operation So this research will discuss about the detection of short circuit faults in the stator winding through leaky flux using a flux sensor that is placed outside the motor and placed radially and using the Fast Fourier Transform (FFT) method. Damage to the short circuit is done by reconstructing the stator winding of the induction motor. There are two variations of short circuit damage, namely short circuit winding 1 to winding 3 and short circuit winding 2 to winding 10 on an induction motor. The short circuit data is then processed using the Fast Fourier Transform method which produces data in the form of voltage to frequency. The results of the percentage of success of short circuit fault detection seen from the loaders have an average percentage of $50 \%$, at no load conditions can detect short circuit faults by $100 \%$. In conditions of short circuit interruption 1-3 has a success percentage of $30 \%$ and short circuit fault $2-10$ by $70 \%$. The existence of this system is expected to be able to anticipate any damage that can cause considerable and fatal losses.
\end{abstract}

Keywords: Stator Winding Short Circuit; Leak Flux Analyzer; Fast Fourier Transform (FFT)

Abstrak-. Pada aplikasi didalam dunia industri penggunaan motor induksi telah banyak digunakan dalam oprasionalnya karena motor induksi memiliki banyak kelebihan, meskipun mempunyai banyak kelebihan motor induksi sendiri juga mempunyai kekurangan yaitu memiliki arus starting yang tinggi. Dalam banyak kasus kerusakan motor induksi kerusakan stator akibat hubung singkat adalah kerusakan yang sering terjadi, kerusakan tersebut dapat menimbulkan kerugian yang cukup besar karena motor dapat berhenti beroprasi. Maka penelitian ini akan membahas mengenai deteksi gangguan hubung singkat pada belitan stator melalui fluks bocor menggunakan sensor fluks yang diletakkan diluar motor dan diletakkan secara radial serta menggunakan metode Fast Fourier Transform (FFT). Kerusakan hubung singkan dilakukan dengan cara merekontruksi belitan stator motor induksi. Ada dua variasi kerusakan hubung singkat yaitu hubung singkat lilitan 1 ke lilitan ke 3 dan hubung singkat lilitan 2 ke lilitan 10 pada motor induksi. Data hasil hubung singkat kemudian diolah menggunakan metode Fast Fourier Transform yang menghasilkan data berupa tegangan terhadap frekuensi. Hasil presentase keberhasilan dtetksi gangguan hubung singkat dilihat dari pembebannya memiliki presentase rata-rata sebesar 50\%, pada kondisi tanpa beban dapat mendeteksi gangguan hubung singkat sebesar 100\%. Dalam kondisi gangguan hubugn singkat 1-3 memiliki presentase keberhasilan sebesar 30\% dan gangguan hubung singkat 2-10 sebesar $70 \%$. Adanya sistem ini diharapkan bisa dapat mengantisipasi adanya kerusakan yang dapat menyebabkan kerugian yang cukup besar dan fatal.

Kata kunci: Hubung Singkat Belitan Stator; Analisa Fluks Bocor; Fast Fourier Transform ( FFT ) 


\section{PENDAHULUAN}

Pada aplikasi industri motor induksi telah banyak digunakan dalam opersionalnya. Hal ini di sebabkan karena motor induksi memiliki kontruksi yang sederhana serta biaya perawatan yang lebih murah di bandingkan motor jenis lain, memiliki keandalan yang lebih tinggi serta tidak memerlukan motor lain untuk staring. Meskipun banyak mempunyai kelebihan motor induksi juga memiliki kekurangan yaitu memiliki arus starting yang tinggi dan untuk mengatur putaran dan frekuensi lebih sulit.

Dalam penggunaannya motor induksi akan mengalami kerusakan sehingga membuat operasional di industri menjadi terhenti, hal itu akan mengakibatkan kerugian pihak industri dalam bentuk financial, tenaga, dan waktu. Gangguan pada motor ada dua jenis yaitu gangguan eksternal dan gangguan internal, gangguan eksternal adalah gangguan yang terletak pada luar motor yaitu: ketidakseimbangan tegangan suplai, beban lebih motor, gangguan fasa, rotor terkunci, dan lainlain, sedangkan gangguan internal adalah gangguan yang berasal dari dalam motor yaitu: gangguan ke tanah, gangguan hubung singkat belitan rotor atau stator, kerusakan bearing, kerusakan rotor dll. Menurut survey yang telah dilakukan presentase gangguan pada komponen biasanya terjadi pada stator $(38 \%)$, bearing $(40 \%)$, rotor $(10 \%)$, dan lainya $(12 \%)$ (Jiang dan Halbelter 2017).

Pada komponen stator gangguan hubung singkat sangat sulit di deteksi, terjadinya gangguan ini dikarenakan adanya kegagalan isolasi pada antar belitan yang mengakibatkan terjadinya gangguan hubung singkat. Saat gangguan ini terjadi maka akan terdapat perubahan fluks bocor disekitar rotor. Perubahan fluks tersebut dapat digunakan untuk mendeteksi gangguan hubung singkat pada belitan stator motor. Untuk mengetahui gangguan tersebut yaitu dengan cara mengalisis perubahan fluks menggunakan sensor yang akan dipasang diluar motor, metode ini lebih efisien dibandingkan metode lain karena tidak mengganggu operasi motor saat bekerja. Metode ini memiliki kelebihan dalam kesederhanaan dalam mengimplementasi dan mendiagnosis secara non-invasif. Penelitian untuk mendeteksi gangguan motor dapat menggunakan metode Motor Current Signature Analysis (MCSA), dimana deteksi gangguan pada motor dilakukan dengan mengalisis spectrum arus pada motor (Alham et al 2018). Pada penelitian tersebut untuk pengolahan spectrum arus dalam medeteksi kerusakan motor menggunakan transformasi wavelet dengan metode quadratic discriminant analysis. Deteteksi gangguan melalui analisa fluks dilakukan oleh achmad hadi et al, 2019, dimana analisa fluks digunakan untuk mendeteksi gangguan eksentrisitas celah udara pada motor induksi, pemilihan sensor fluks sebagai deteksi kerusakan motor induksi di karenakan memiliki keakurasian yang tinggi. Pengambilan data menggunakan sensor fluks dilakukan secara axial, yaitu mensejajarkan sensor fluks terhadap stator. Dari data tersebut kemudian diolah menggunakan metode fast fourier transform (FFT) (Achmad hadi et al 2019).
Berdasarkan penelitian diatas maka pada penelitian ini melakukan pengembangan yaitu melakukan deteksi gangguan hubung singkat pada stator motor induksi 3 fasa menggunakan sensor fluks eksternal. Pengambilan data deteksi hubung singkat dilakukan menggunakan sofware Labview dan menggunakan DIAdem sebagai pengolahan data dengan menggunakan metode fast fourier transform (FFT). Hasil penelitian inidapat digunakan sebagai alternatif metode deteksi gangguan pada motor induksi. Metode ini dapat mendeteksi kondisi motor dalam keadaan rusak dan sehat. Kelebihan dari penelitian ini adalah dapat mendeteksi gangguan hubung singkat pada saat motor berkerja dan tanpa harus membongkar motor tersebut sehingga tidak merugikan dalam hal tenaga dan biaya untuk perbaikan motor. Setelah melakukan percobaan dan menganalisa pada penelitian ini memperoleh hasil, dimana rata-rata keberhasilan dalam percobaan ini ialah sebesar $50 \%$. Dalam variasi pembebanan pada pembebanan $0 \%$ mendapatkan presentase keberhasilan sebesar $100 \%$ untuk variasi pembebanan $25 \%$ dan $50 \%$ mendapatkan presentase keberhasialan sebesar 50\% lalu untuk variasi pembebanan $75 \%$ dan $100 \%$ mendapatkan presentase keberhasilan sebesar 25\%. Hasil presentase keberhasilan deteksi hubung singkat menurut variasi gangguan hubung singkat mendapatkan presentase $70 \%$ pada variasi gangguan hubung singkat 2-10 dan $30 \%$ presentase keberhasilan pada variasi gangguan hubung singkat 1-3. Untuk keberhasilan gangguan hubung singkat sangat efektif dilakuakan pada saat motor induksi berada pada kondisi tanpa beban, di karenakan pada saat kondisi tanpa beban dalam penelitian ini presentase keberhasilan bisa mencapai $100 \%$.

\section{TINJAUAN PUSTAKA}

\subsection{Motor Induksi 3 Fasa}

Di dalam dunia industri motor induksi 3 fasa sangat sering di gunakan motor induksi memiliki konstruksi yang kuat , memiliki karekteristik yang baik dan biaya perawatannya yang cukup terjangkau. Fungsi motor adalah untuk merubah energi listrik menjadi energi gerak menggunakan konsep induksi. Cara kerja motor induksi adalah arus yang mengalir pada stator akan menimbulkan medan putar yang akan membangkitkkan fluks pada rotor dan membuat rotor berputar

\subsection{Prinsip kerja motor induksi}

Motor induksi mulai berkerja pada saat terminal tiga fasa pada stator motor induksi diberi suplai tegangan tiga fasa seimbang, maka akan mengalirkan arus pada konduktor di tiap belitan fasa stator dan akan menghasilkan fluksi bolakbalik. Amplitudo fluksi per fasa yang dihasilkan berubah secara sinusoidal dan menghasilkan fluks resultan (medan 
putar) dengan magnitud yang nilainya konstan yang berputar dengan kecepatan sinkron.

Karena belitan rotor merupakan rangkaian tertutup, baik melalui cincin ujung (end ring) ataupun tahanan luar, maka arus akan mengalir pada konduktor-konduktor rotor. Karena konduktor-konduktor rotor yang mengalirkan arus ditempatkan di dalam daerah medan magnet yang dihasilkan stator, maka akan terbentuklah gaya mekanik (gaya lorentz) pada konduktor-konduktor rotor. Hal ini sesuai dengan hukum gaya lorentz yaitu bila suatu konduktor yang dialiri arus berada dalam suatu kawasan medan magnet, maka konduktor tersebut akan mendapat gaya elektromagnetik (gaya lorentz)

Seperti yang telah disebutkan di atas maka motor akan tetap berputar bila kecepatan medan putar lebih besar dari pada kecepatan putaran rotor $(n s>n r)$. Apabila $n s=n r$, maka tidak ada perbedaan relatif antara kecepatan medan putar $(n s)$ dengan putaran rotor $(n r)$, atau dengan kata lain slip $(s)$ adalah nol. Hal ini menyebabkan tidak adanya ggl terinduksi pada kumparan rotor sehingga tidak ada arus yang mengalir, dengan demikian tidak akan dihasilkan gaya yang dapat menghasilkan kopel untuk memutar rotor.

\subsection{Gangguan stator}

Gangguan stator dapat dua jenis, yaitu: gangguan di belitan stator dan gangguan di inti stator.Gangguan di belitan stator dapat disebabkan oleh: temperatur yang tinggi pada inti dan belitan, kontaminasi akibat minyak, kelembaban dan lain-lain, kerusakan pada ujung belitan, hubung singkat, pembebanan pengasutan, electric discharge, bocor pada sistem pendinginan. Awal mula terjadinya gangguan hubung singkat adalah dengan munculnya partial discharge dikarenakan faktor tekanan lingkungan dan juga cacat bawaan dari motor. Terjadinya hubung singkat dimulai bertahap dari hubung singkat temporer dengan durasi pendek arus pendek (impedansi tinggi) menuju gangguan permanen arus tinggi.

Kerusakan yang terjadi pada belitan stator dapat menyebabkan motor induksi mengalami ketidak normalan putaran sehingga arus stator mengandung harmonisa dengan frekuensi kerusakan bisa diprediksi dengan persamaan dibawah ini

$$
\text { Fst }=\mid \text { fs } \pm \text { fp } \mid
$$

Dimana fst merupakan frekuensi kerusakan stator, fp merupakan frekuensi prediksi kerusakan belitan Stator, dan fs merupakan frekuensi sumber listrik (50 atau $60 \mathrm{~Hz}$ ). Kerusakan yang terjadi pada belitan Stator memberikan komponen harmonic dalam spectrum arus pada frekuensi. sehingga frekuensi kerusakan bisa terlihat dengan persamaan berikut:

$$
\text { fst }=\mathrm{fs}\left[\frac{1-\mathrm{s}}{\mathrm{p}}\right]
$$

Dimana fst merupakan frekuensi prediksi kerusakan belitan stator, fs merupakan frekuensi sumber listrik (50 atau $60 \mathrm{~Hz}$ ), p merupakan jumlah pasang kutubdan s merupakan nilai slip kecepatan.

\subsection{Fluks analisis}

Metode dalam memonitoring suatu kondisi mesin, telah berkembang dengan menggunakan analisis magnetic field. Stray flux adalah fluk magnet yang terradiasi oleh bagian dalam body mesin dan terhubung secara langsung pada magnetic mesin. Adanya stray flux dihasilkan oleh arus stator dan rotor yang mempunyai perbedaan komponen spectral. Memonitor fluks bocor karena adanya gangguan merupakan Teknik yang sama seperti mendeteksi perubahan arus harmonisa secara tidak langsung melalui spektrum sinyal fluks. Kelebihan dari metode Analisa fluks ini adalah kemampuan dalam pengukuran non-invasif, dapat diimplementasikan secara sederhana, dan dengan biaya yang murah. Jika dibandingkan dengan Analisa menggunakan metode MCSA, Analisa fluks memiliki kelebihan lebih sensitif, handal, dan cocok digunakan untuk medeteksi gangguan awal di mesin induksi. Salah satu sensor yang bisa digunakan untuk mengukur fluks yaitu Rogowski koil. Rogowski koil adalah suatu tranduser dari arus menjadi tegangan. Prinsip dari sensor tersebut adalah karena ketidakhomogenan dari fluks magnet yang dihasilkan oleh konduktor utama Rogowski koil dari koil sekunder. Memonitor fluks bocor karena adanya gangguan merupakan teknik yang sama seperti mendeteksi perubahan harmonisa secara tidak langsung melalui spektrum sinyal fluks. Kelebihan dari metode analisa fluks ini adalah kemampuannya dalam pengukuran secara non-invasif, dapat diimplementasikan secara sederhana, dan dengan biaya yang murah. Jika dibandingkan dengan Analisa menggunakan metode MCSA, Analisa fluks memiliki kelebihan lebih sensitif, handal, dan cocok digunakan untuk medeteksi gangguan awal di mesin induksi. Namun untuk mengukur besarnya stray flux ini akan sulit karena tergantung dimana stray flux ini muncul di badan motor induksi. Diperlukan sensor yang akurat dan mempunyai kesensitifitas yang tinggi agar mendapatkan hasil pengukuran stray flux yang akurat dan maksimal. Sensor magnet sendiri terdiri dari dua jenis yaitu primary magnegtic sensor dan secondary magnetic sensor. Primary magnetic sensor sering disebut dengan magnetometer, yaitu alat yang digunakan untuk mendeteksi ada atau tidaknya benda logam dengan cara mendeteksi fluks/anomali magnetik. Dari teknologi yang sudah berkembang terdapat beberapa jenis magnetometer yang berfungsi dalam elektronik instrument portable. Penelitian kali ini menggunakan sensor fluks dengan jenis ELF Gauss meter. Alat pengukuran ini digunakan untuk menangkap stray flux yang keluar dari badan motor. Salah satu jenis teknologi dalam magnetometer adalah menggunakan sensor koil. Sensor koil ini dibuat berdasarkan hukum Faraday. Menurut hukum induksi faraday, gaya gerak listrik dihasilkan dari loop tertutup ketika diletakkan pada tempat yang mempunyai medan magnet bervariasi terhadap waktu. Tegangan induksi atau gaya gerak listrik yang diinduksikan pada sepanjang koil dalam kumparan sebanding dengan perubahan medan magnet dalam kumparan. Supaya koil dapat bekerja, kumparan harus dalam medan magnet yang 
bervariasi atau bergerak melalui medan magnet. Koil yang terbuat dari tembaga dengan 47 lilitan dan luas penapang 5 $\mathrm{cm} 2$ digunakan pada probe sensor ini. Sensor coil sangan cocok digunakan karena sensor koil mempunya sensitivitas lebih tinggi dibandingkan Hall effect sensor pada frekuensi lebih dari $30 \mathrm{kHz}$. Keluaran sensor koil ini akan menyampai tinggi maksimal tegangan 6Volt yang dihasilkan dari kerapatan fluks magnet $200 \mathrm{mG}$ dan frekuensi $200 \mathrm{kHz}$

Sensor Fluks Sensor ini terbuat dari bahan khusus vitrovac 6025, dan duan buah probe, yaitu probe yang digunakan untuk kumparan primer (pengeksitasi atau exitation coil) dan probe skunder yang digunakan untuk penangkap atau pick up coil. Sensor ini emiliki sensisitivitas yang meningkat dengan meningkatnya jumlah beltan kumparan sekunder atau mengkatnya suhu operasi (djamal et al., 2007). Sensor fluks yang di pakai pada penelitian ini menggunakan sensor ELF Gaussmeter

\subsection{Fast Fourier Transform (FFT)}

FFT (Fast Fourier Transform) adalah suatu algoritma untuk menghitung DFT (Discrete Fourier Transform) dengan lebih cepat dan efisien. FFT digunakan untuk mempresentasikan sinyal dalam domain waktu diskrit dan domain frekuensi. Kelebihan menggunakan FFT adalah mengurangi kompleksitas transformasi yang dilakukan DFT, dan juga waktu transformasi yang lebih cepat. FFT dipergunakan untuk mengurangi kompleksitas transformasi yang dilakukan dengan DFT

\section{METODE PENELITIAN}

\subsection{Konfigurasi sistem}

Untuk mendeteksi gangguan hubung singkat dalam penelitian ini dilakukan melalui analisa frekuensi di area sekitar motor induksi dengan menggunakan sensor fluks untuk pengambilan data. Hasil dari pengambilan data diolah melalui metode fast fourier transform. Untuk itu beberapa peralatan yang di butuhkan pada penelitian ini adalah sumber tegangan $\mathrm{AC}$, motor induksi 3 phasa, sensor fluks, yang dapat di lihat pada gambar 1:

[Figure 1 about here.]

Sumber tegangan AC 380 volt dalam penelitian ini digunakan sebagai sumber tegangan untuk menjalankan motor induksi 3 fasa dengan kapasitas motor sebesar 2 HP atau sama dengan $1.5 \mathrm{KW}$. Motor induksi 3 fasa diberikan beban mekanin dan elektrik berupa generator dan lampu yang difungsikan sebagai sistem pengukuran. Agar beban dan motor induksi dapat menyatu maka cara yang dilakukan adalah dengan mengkopel motor dengan generator yang disambungkan ke lampu. Adapun alat-alat penunjang yang digunakan dalam penelitian ini untuk pengukuran sinyal tegangan dalam penelitian ini menggunakan komputer yang memiliki perangkat lunak berupa LabView, Diadem, serta NI DAQ9755 yang berfungsi untuk akuisisi data tegangan pada penelitian ini. Alat akuisisi data tegangan akan terintegrasi dengan perangkat lunak LabView yang bertujuan agar mempermudah untuk melakukan pemilihan data frekuensi sampling. Hasil data pengukuran yang sudah di dapat selanjutnya akan diolah menggunakan metode fast fourier transform, data hasil yang sudah di olah menggunakan metode dast fourier transform selanjutnya akan diolah kembali kedalam sofware Matlab agar mendapatkan Domain Amplitudo terhadap frekuensi.

\subsection{Pembebanan Pada Motor Induksi}

Pada motor induksi beban maksimal yang diberikan dibatasi dengan kapasitas daya motor sekitar 1500 Watt, beban motor induksi akan diberikan dalam bentuk persen dimana $100 \%$ adalah beban maksimum atau 1500 watt dan arus nominal pada rating motor sebesar 3,68 A hasil tersebut didapat dari penjumlahan beban yang diterima oleh motor induksi. Variasi beban dalam percobaan ini memiliki beberapa variasi pembebanan dimana kondisi awal yang diberikan pada motor adalah beban $0 \%$ yaitu dimana motor tanpa beban. Kondisi yang berikutnya ialah motor akan dihubungkan dengan generator sinkron dan output generator dihubungkan dengan beban lampu pijar yang secara bertahap hingga memcapai beban $25 \%$, beban $50 \%$, beban $75 \%$ dan beban penuh $100 \%$ Data pembebanan yang di maksud diatas dapat di lihat pada pada table berikut:

[Table 1 about here.]

Pembebanan yang memiliki beberapa variasi ini bertujuan untuk mengetahui perbedaan yang di timbulkan akibat hubung singkat di setiap variasi pembebanan. Sistem kerja Pembebanan ini adalah beban generator memberikan beban lampu yang membuat daya output pada generator akan ikut naik apabila daya keluaran generator semakin besar maka torsi generator akan ikut naik. Hal ini membuat generator yang dikopel dengan motor induksi akan membuat kecepatan pada motor induksi turun. Hal itu yang membuat motor menjadi terbebani sesuai kenaikan beban lampu yang diberikan. Untuk beban lampu yang di berikan pada percobaan ini ialah beban lampu sebanyak 10 buah dimana masing masing lampunya memiliki daya 100 watt.

\subsection{Rekrontuksi gangguan hubung singkat}

Motor induksi normal memiliki belitan spul sebanyak 12 terminal yang terpasang pada motor induksi iala keluaran dari setiap belitan pada stator, untuk membuat motor berada dalam kondisi hubung singkat maka dilakukan rekrontruksi hubung singkat dengan cara menghubungkan kabel berdiameter kecil pada terminal yang telah di tentukan. Dalam penelitian ini rekrontuksi Hubung singkat di lakukan pada lilitan ke 1 yang di hubungkan ke lilitan ke 3 dan lilitan 2 di hubungkan ke lilitan 10 pada fasa $R$. 


\section{$\pi[\vec{A}] 7$ Journal of Electrical and Electronic Engineering-UMSIDA ISSN 2460-9250 (print), ISSN 2540-8658 (online)

3.4 Perancangan Sistem Pengukuran dan Pengolahan Data

Dalam penelitian ini pengambilan data tegangan pada stator motor induksi menggunakan alat bantu ELF Gaussmeter yang berfungsi sebagai input dari NI-DAQ9775, pada probe yang di miliki oleh ELF gaussmeter ini bisa mendeteksi fluks yang berada di area stator. Fluks magnetik yang di tnagkap oleh Probe tersebut kemudian dibaca oleh NI-DAQ-9775 sebagai sinyal tegangan. Channel yang dipakai di NI-DAQ-9775 menggunakan Channel a0. Untuk pengukuran sinyal tegangan sendiri dilakukan melalui Sofware LabVIEW Sofware ini yang digunakan sebagai program utama agar dapat menampilkan dan memerintahkan untuk akuisisi data sinyal tegangan yang berada pada area stator motor induksi 3 fasa. Sofware LabVIEW biasa dikenal dengan sebutan VI atau Virtual Instruments yang dikarena tampilan pada sistem operasinya dapat meniru sebuah peralatan instrumentasi. Terdapat beberapa komponenkomponen penting di dalam sofware LabVIEW, yaitu front panel dan block diagram. Front panel merupakan bagian dari windows yang tampilan utama dari sofware LabVIEW. Front panel difungsikan untuk membangun sebuah VI, menjalankan program dan mendebug program. Diagram blok ialah bagian windows yang berisi source code yang menggunakan fungsi representasi grafis untuk mengontrol sebuah objek dari front panel. Pengolahan sinyal tegangan yang berada diarea stator dilakukan menggunakan Sofware DIAdem. DIAdem Berfungsi untuk menampilkan sinyal dari hasil pengambilan data tegangan yang berasal dari LabVIEW yang biasanya berformat TDMS, isi dari diagram block terdapat While loop yang didalamnya nanti ditambahkan meansurment akuisi data sinyal tegangan.

Dalam penelitian ini difungsikan untuk pengolah sinyal tegangan dari yang semulanya adalah berupa hasil dari domain waktu yang diubah menjadi domain frekuensi dimana nantinya dilakukan pengamatan data perubahan bentuk frekuensi saat motor mengalami gangguan hubung singkat. Untuk menganalisa data tegangan dalam penelitian menggunakan algoritma Fast Fourier Transform (FFT) yang mengubah sinyal tegangan dari domain waktu ke domain frekuensi.

\section{HASIL PENGUJIAN DAN ANALISA DATA}

Agar hasil yang di dapat akurat pada saat analisa, maka dilakukan pengambilan data saat kondisi motor berbeban hal ini dilakukan agar bisa menganalisa efek spektrum frekuensi sinyal tegangan di motor induksi saat dalam kondisi berbeban. Pembeban tersebut juga dilakukan pada saat motor induksi berada pada kondisi hubung singkat. Supaya efek hubung singkat pada motor induksi di dapat maka dilakukanlah pengkopelan ke generator dan dilakukan pembebanan berupa generator. Pembebanan didalam penelitian ini dinyatakan dalam bentuk persen, supaya mendepatkan hasil yang bervariasi sehingga dapat di analisa maka pembebanan dalam penelitian ini dibuat sebanyak 5 variasi pembebanan. Proses ambil data yang bertujuan untuk menganalisa gangguan hubungsingkat menggunakan satu variasi frekuensi resolusi yang dilakukan sebanyak 5 kali

\subsection{Perhitungan Persentase Pembebanan}

Variasi pembebanan yang digunakan dalam penenelitian ialah pembebanan mekanik yang berupa pengkopelan motor induksi dengan generator sinkron yang bertujuan ntuk membuat beban bervariasi. Untuk memberi beban bervarisi pada generator sinkron maka diberilah generator sinkron dengan beban elktris yang berupa lampu pijar. Variasi pembebanan sendiri ditentukan dalam bentuk persen mulai dari $0 \%$ sampai dengan $100 \%$ maka langkah yang diambil agar bisa mengaur beban motor induksi ialah dengan mengukur arus dan cos phi di stator motor induksi untuk menentukan daya motor induksi pada kondisi presentase tertentu. Untuk langkah awal yang dilakukan ialah mengambil data motor pada saat motor induksi tidak di kopel dengan generator, selanjutnya motor dikopel dengan generator yang sudah di hubungkan dengan pembebanan berupa lampu pijar yang bervarisi hingga sampai arus pada motor berada pada angka maksimum arus motor/beban penuh. Arus maksimal/beban penuh pada nameplate motor induksi yang dipakai ialah 3,68A. Acuan yang di gunakan pada pembebanan motor induksi ialah beban penuh. Power quality ialah alat yang digunakan untuk pengukurannya. Besarnya daya lampun yang di gunakan dalam penelitian ini ialah 100 watt.

\subsection{Pengukuran Slip pada Motor Kondisi Normal dan Kondisi Eksentrisitas}

Agar bisa menentukan frekuensi gangguan hubungsingkat pada area fundamental maka di perlukan nilai slip motor induksi. Nilai slip motor bisa didapatkan dari perhitungan ketetapan nameplate pada motor induksi untuk ns dan $\mathrm{nr}$ dapat di ambil dari hasil pengukuran rpm yang di ukur pada sat motor beroprasi. Berdasarkan persamaan (2.3), hasil dari perhitungan yang didapatkan digunakan untuk mengetahui nilai frekuensi rotor yang kemudia di jumlahkan dengan nilai frekuensi sumbuer agar dapat mengetahui titik frekuensi gangguan hubungsingkat. Contoh perhitungan untuk mencari nilai slip pada beban $0 \% S=\frac{1500-1489}{1500}=0,0073$ Frekuensi yang muncul disekitaran frekuensi fundamental yang memiliki pola berbeda beda frekuensi tersebut yang dinamakan frekuensi gangguan.

\subsection{Hasil Analisa Deteksi Gangguan Hubung Singkat}

Frekuensi gangguan hubung singkat yang digunakan dalam penelitian ini menggunakan satu variasi frekuensi yaitu $0,1 \mathrm{~Hz}$. Frekuensi $0,1 \mathrm{~Hz}$ dipilih karena untuk memperpanjang waktu pengambilan $10 \mathrm{sec}$ dimana banyak data yangdipakai ialah $50 \mathrm{Ks}$ lalu frekuensi sampelnya memakai nilai sebesar $5 \mathrm{Ks} / \mathrm{s}$. Untuk pengambilan data pada frekuensi $0,1 \mathrm{~Hz}$ dilakukan sebanyak 4 kali hal ini bertujuan 
utuk agar bisa memilih data yang terbaik pada setiap data. Saat proses analisa agar mendapatkan hasil yang maksimal maka menganalisa deteksi gangguan hubungsingkat dilakukan dengan memberikan pembebanan yang bervariasi pembebanan yang di maksud yaitu pembebanan $0 \%, 25 \%$, $50 \%$, $75 \%$, dan $100 \%$. Pengujian yang dilakukan untuk penentu motor induksi teridentifikasi dalam keadaan gangguan hubung singkat ialah dengan mengamati adanya perbandingan kenaikan pada amplitudo di frekuensi gangguan hubungsingkat. Perbandingan dapat dilihat pada saat motor kondisi normal dan pada saat motor kondisi terjadi gangguan hubung singkat. Setelah dilakukan analisa frekuensi gangguan hbung singkat muncul pada frekuensi $25 \mathrm{~Hz}$ dan frekuensi $75 \mathrm{~Hz}$ di sekitar frekuensi fundamental.

\subsection{Analisa spektrum frekuensi gangguan hubung singkat pada beban $0 \%$}

Di dalam sub bab ini akan dijelaskan mengenai analisa frekuensi gangguan hubung singkat pada beban $0 \%$ yang menggunakan metode FFT (fast fourier transform) di tiga kondisi. Pengambilan data dalam kondisi ini dimulai dari saat motor kondisi normal lalu motor dalam kondisi gangguan hubung singkat pada lilita 1-3 dan dilanjutkan pada motor gangguan hubung singkat pada lilitan 2-10. Hasil sinyal pada motor gangguan hubung singkat dibandingkat dengan motor yang kondisi normal.

[Figure 2 about here.]

[Figure 3 about here.]

[Figure 4 about here.]

[Figure 5 about here.]

Gambar 5 Hasil rata-rata pembebanan 0\% sampel 1 sampai 4 di kondisi motor induksi normal, gangguan hubung singkat 1-,dan gangguan hubung singkat 2-10. *warna ungu adalah hasil dari nilai rata-rata yang mengalami kenaikan ampitudo

Didalam table pembebanan $0 \%$ merupakan hasi dari analisa percobaan dalam kondisi tanpa beban. Untuk banyaknya sampel yang di ambil pada percobaan tersebut adalah sebanyak 4 kali, terlihat dalam tabel untuk sampel ke 1 hingga sample ke 4 pada setiap kondisi memperlihatkan adanya lonjakan yang terjadi. Pada table dapat di lihat hasil perhitugan di mana pada kolom yang berwarna ungu adalah hasil dari rata-rata sedangkan kolom yang memiliki warna merah ialah kolom yang berfungsi jika nilai hubung singkat dibandingkan dengan motor normal menandakan peringatan lalu jika tabel berwarna hijau maka menandakan bila motor terdeteksi mengalami gangguan. Dalam hasil analisa di percobaan tanpa bebain ini terlihat kenaikan amplitudo di setiap kondisi hubung singkat, didalam kondisi normal nilai rata-rata $(f s-f r)$ sebesar $-13,0925 \mathrm{~dB}$ dan $-23,7275 \mathrm{~dB}\left(f_{s}+f r\right)$ sedangkan dalam mkeadaan gangguan hubung singkat 1-3 memiliki nilai rata-rata $(f s-f r)-12,02 \mathrm{~dB}$ dan $-22,37 \mathrm{~dB}$ $(f s+f r)$, lalu pada gangguan hubung singkat 2-10 nilai ratarata $(f s-f r)-12,655 \mathrm{~dB}$ dan $-23,365 \mathrm{~dB}(f s+f r)$, hasil perhitungan analisa menunjukan kenaikan amplitudo pada gangguan hubung singkat 1-3 pada sisi $(f s-f r)$ sebesar 1,0095 $\mathrm{dB}$ dan $1,3575 \mathrm{~dB}$ pada sisi $(f s+f r)$, sedangkan pada kondisi gangguan hubung singkat 2-10 kenaikan amplitudo sebesar $0,4375 \mathrm{~dB}$ pada sisi $(f s-f r)$ dan 0,3625 pada sisi $(f s+f r)$. Maka dapat di simpulkan bahwa pada keadaan tanpa beban percobaan ini dapat mendeteksi adanya gangguan hubung singkat.

\subsection{Analisa spektrum frekuensi gangguan hubung singkat pada beban $75 \%$}

Di dalam sub bab ini akan dijelaskan mengenai analisa frekuensi gangguan hubung singkat pada beban $75 \%$ yang menggunakan metode FFT (fast fourier transform) di tiga kondisi.

[Figure 6 about here.]

[Figure 7 about here.]

[Figure 8 about here.]

Gambar 9 Hasil rata-rata pembebanan $75 \%$ sampel 1 sampai 4 di kondisi motor induksi normal, gangguan hubung singkat 1-3, dan gangguan hubung singkat 2-10.

[Figure 9 about here.]

Pada hasil dari pembebanan $75 \%$ hasil analisa memperlihatkan kenaikan amplitudo pada kondisi gangguan hubung singkat 1-3 hanya pada sisi $(f s+f r)$ kenaikan amplitudo tersebut sebesar 1,3475 dB, sedangkan pada sisi ( $f s-f r$ ) justru mengalami penuruan amplitudo, berbeda dengan kondisi hubung singkat 1-3 di hubung singkat 2-10 kenaikan amplitudo justru terjadi pada sisi ( $f s-f r)$, kenaikan amplitudo sendiri sebesar $0,3125 \mathrm{~dB}$ sedangkan pada sisi $(f s+f)$ justru mengalami penurunan.

\subsection{Analisa Persentase Keberhasial Deteksi Gangguan Hubung Singkat}

Agar dapat mengetahui seberapa besar presentase keberhasilan deteksi gangguan hubung singkat maka perlu dilakukan perhitungan presentase keberhasilan menggnakan persamaan dibaweah ini.

$$
\%=\frac{\text { Jumlah data yang terdeteksi gangguan }}{\text { Banyak data }} \times 100
$$

Jumlah data yang terdeteksi gangguan hubungsingkat ialah data yang memiliki nilai amplitudo pada kondisi gangguan lebih tinggi dari pada nilai amplitudo pada motor normal. 
4.7 Presentase Keberhasilan Deteksi Gangguan Hubung Singkat Dengan Menggunakan Hasil Data Rata-Rata Dari Setiap Sampel Berdasarkan Pembebanan

Setelah menganalisa perhitungan pada setiap pembebanan maka di dapatkan hasil rata-rata dari setiap pembebanan. Penggunaan sensor fluks terlihat dapat mendeteksi adanya gangguan hubung singkat, hal ini dilihat dari hasil analisa pada saat kondisi normal sensor fluks dapat mendeteksi adanya lonjakan amplitude yang mungkin di sebabkan oleh cacat pabrik. Lonjakan amplitudo yang lebih tinggi dibandingkan saat kondisi normal dapat dijadikan bahan untuk menganalisa prese ntase keberhasilan yang dapat dilihat pada Tabel

\section{[Figure 10 about here.]}

* Warna hijau adalah nilai yang terdeteksi hubung singkat Gambar diatas merupakan hasil analisa presentase keberhasilan deteksi gangguan hubungsingkat data kenaikan amplitudo pada rata-rata sample digunakan untuk menganalisa presentasi keberhasilan gangguan hubung singkat bertujuan untuk mendapatkan hasil yang real dipenelitian ini. Pada pembebanan $0 \%$ penelitian ini dapat mendeteksi adanya gangguan sebesar $100 \%$,namun pada kondisi pembebanan $25 \%$ dan $50 \%$ penelitian ini hanya dapat mendetemsi gangguan hubung singkat sebesar $50 \%$. Pada kondisi $75 \%$ hingga $100 \%$ hanya dapat mendeteksi gangguan hubung singkat sebesar $25 \%$ saja.

\section{UCAPAN TERIMA KASIH}

Ucapan terimakasih kepada Lab mesin listrik teknik elektro Universitas Hang Tuah Surabaya yang telahberkontribusi dalam penelitian ini sehingga penelitian dapat berjalan dengan baik.Ucapan terimakasih kepada Lab Mesin Listrik Teknik Elektro Universitas Hang Tuah Surabaya yang telah berkontribusi dalam penelitian ini sehingga penelitian dapat berjalan dengan baik.

\section{REFERENSI}

[1] C. Jiang, S. Li and T. G. Habetler, "A review of condition monitoring of induction motors based on stray flux," 2017 IEEE Energy Conversion Congress and Exposition (ECCE), Cincinnati, OH, 2017, pp. 5424-5430

[2] N. R. Alham, D. A. Asfani, I. M. Y. Negara and B. Y. Dewantara, "Analysis of load and unbalance voltage on air gap eccentricity in detection of three phase induction motor," 2018 International Conference on Information and Communications Technology (ICOIACT), Yogyakarta, 2018, pp. 566-571.

[3] Liu, Zheng, et al. "Non-invasive winding fault detection for induction machines based on stray flux magnetic sensors." 2016 IEEE Power and Energy Society General Meeting (PESGM). IEEE, 2016.

[4] J. Penman, H. G. Sedding, B. A. Lloyd and W. T. Fink, "Detection and location of interturn short circuit in the stator windings of operating motors," in IEEE
Transactions on Energy Conversion, vol. 9, no. 4, pp. 652-658, Dec. 1994.

[5] R. Romary, R. Pusca, J. P. Lecointe and J. F. Brudny, "Electrical machines fault diagnosis by stray flux analysis," 2013 IEEE Workshop on Electrical Machines Design, Control and Diagnosis (WEMDCD), Paris, 2013, pp. 247-256.

[6] A. Hermawan, et al. "Deteksi Kegagalan Isolasi Pada Belitan Stator Motor Induksi Bebasis Fast Fourier Transform," 2019 CITEE, Yogyakarta, 2019.

Conflict of Interest Statement: The author declares that the research was conducted in the absence of any commercial or financial relationships that could be construed as a potential conflict of interest.

Copyright (C) 2021 Author [s]. This is an open access article distributed under the terms of the Creative Commons Attribution License (CC BY). The use, distribution or reproduction in other forums is permitted, provided the original author(s) and the copyright owner(s) are credited and that the original publication in this journal is cited, in accordance with accepted academic practice. No use, distribution or reproduction is permitted which does not comply with these terms.

Received: 2021-02-17

Accepted: 2021-02-28

Published: 2021-04-03 
$\pi \sqrt{A} \sqrt{A} \square \int$ Journal of Electrical and Electronic Engineering-UMSIDA

ISSN 2460-9250 (print), ISSN 2540-8658 (online)

Vol. 5, No. 1, April 2021

DAFTAR TABEL

10.21070/jeeeu.v5i1.1281

I Pembebanan Pada Motor Induksi .

. .97 


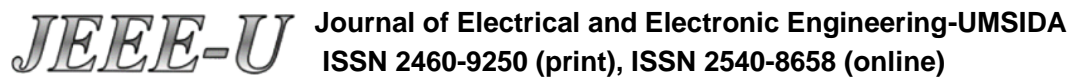

Vol. 5, No. 1, April 2021

Table 1. Pembebanan Pada Motor Induksi

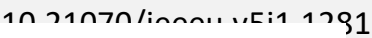

\begin{tabular}{|c|c|c|}
\hline \multirow{2}{*}{ NO } & \multicolumn{2}{|c|}{ PEMBEBANAN } \\
\cline { 2 - 3 } & $\begin{array}{c}\text { PERSENTASE } \\
\text { BEBAN }\end{array}$ & $\begin{array}{c}\text { ARUS } \\
\text { BEBAN }\end{array}$ \\
\hline 1 & $0 \%$ & $2,3 \mathrm{~A}$ \\
\hline 2 & $25 \%$ & $2,72 \mathrm{~A}$ \\
\hline 3 & $50 \%$ & $3,05 \mathrm{~A}$ \\
\hline 4 & $75 \%$ & $3,367 \mathrm{~A}$ \\
\hline 5 & $100 \%$ & $3.68 \mathrm{~A}$ \\
\hline
\end{tabular}




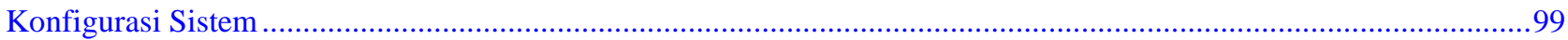

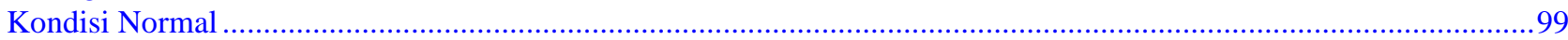

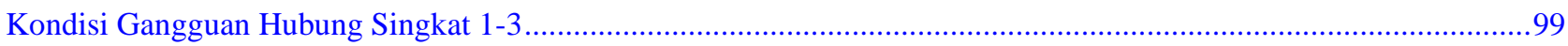

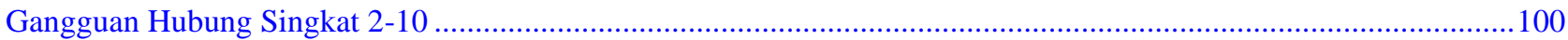

Hasil Rata-Rata Pembebanan 0\% sampel 1 sampai 4 di kondisi motor induksi normal ......................................100

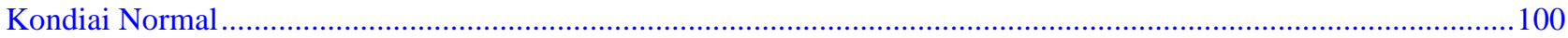

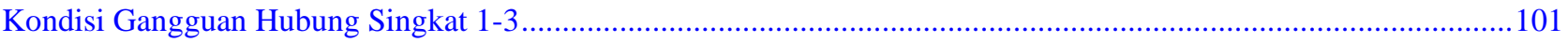

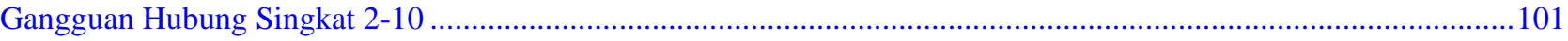

9 Hasil Rata-Rata Pembebanan 75\% Sampel 1 Sampai 4 Di Kondisi Motor Induksi Normal.....................................102

10 Diatas Merupakan Hasil Analisa Presentase Keberhasilan ........................................................................ 102 


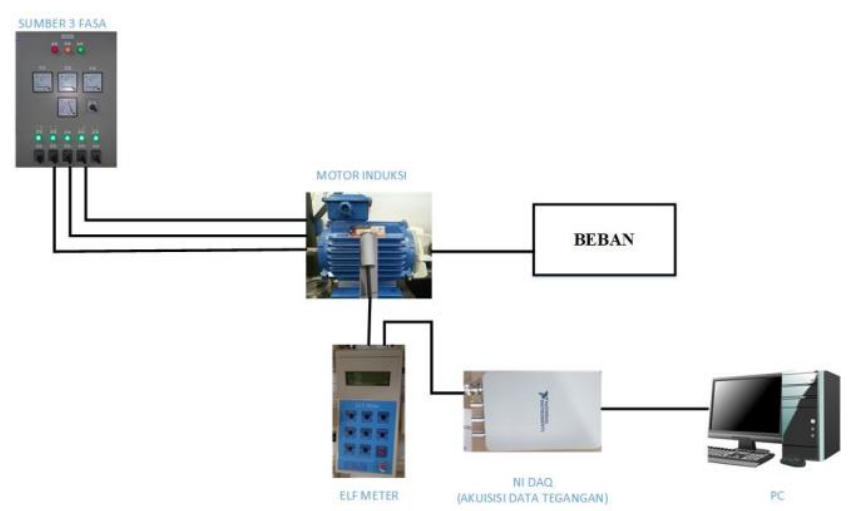

Figure 1. Konfigurasi Sistem

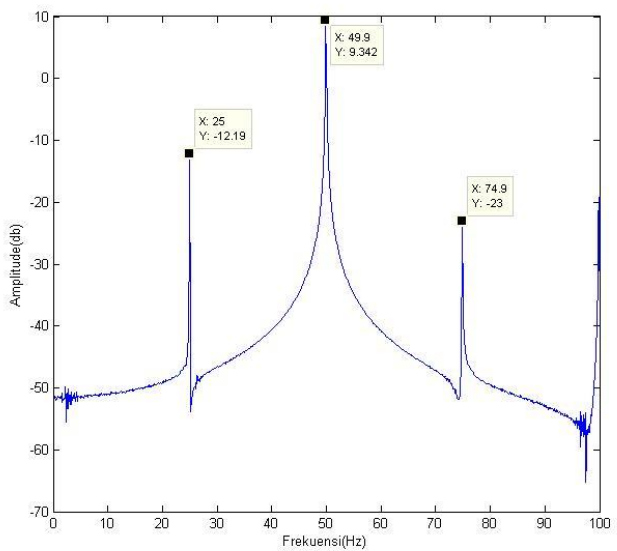

Figure 2. Kondisi Normal

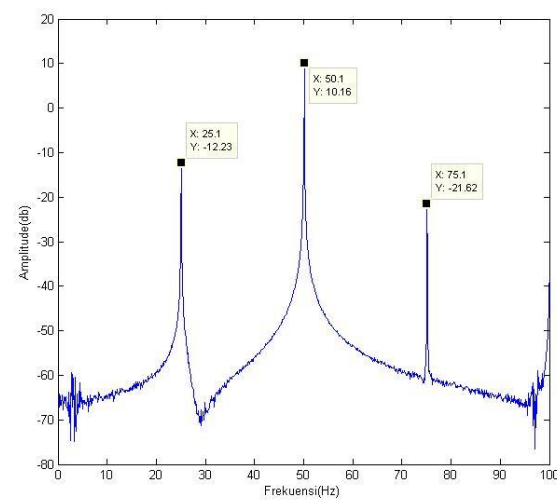

Figure 3. Kondisi Gangguan Hubung Singkat 1-3 


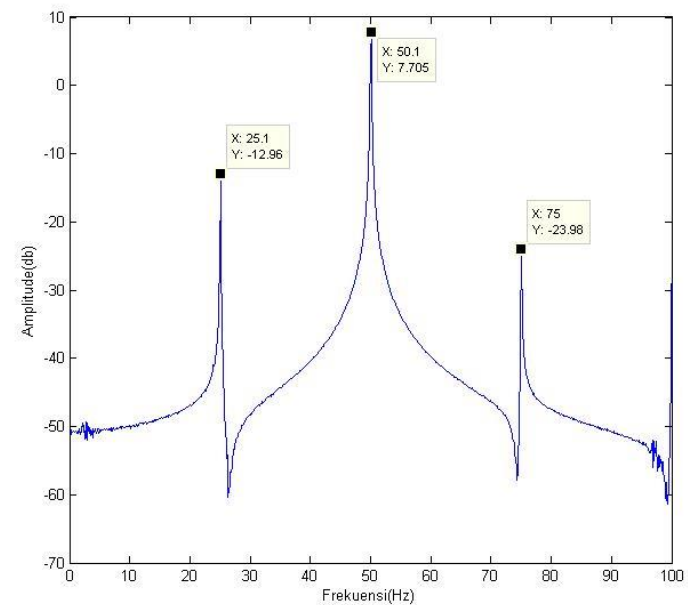

Figure 4. Gangguan Hubung Singkat 2-10

\begin{tabular}{|c|c|c|c|c|}
\hline & $\begin{array}{l}\text { Jumlah } \\
\text { Sampel }\end{array}$ & $\begin{array}{c}(s+f) \\
(\mathrm{dB})\end{array}$ & $\begin{array}{l}\text { Frelkuensi } \\
\text { Fundamental } \\
\text { (dB) }\end{array}$ & $\begin{array}{c}(A s+f) \\
(\mathrm{dB})\end{array}$ \\
\hline \multirow{4}{*}{$\begin{array}{c}\text { Nilai } \\
\text { amplitudo } \\
\text { (dB) }\end{array}$} & Sampel 1 & $-12,79$ & 9,342 & -23 \\
\hline & Sampel 2 & $-13,06$ & 7,716 & $-24,04$ \\
\hline & Sampel 3 & $-12,82$ & 7,692 & $-23,19$ \\
\hline & Sampel 4 & $-13,7$ & 6,258 & $-24,68$ \\
\hline \multicolumn{2}{|c|}{ Rata - Rata } & $-13,0925$ & 7,752 & $-23,7275$ \\
\hline & & Aan & jung Singlicat 1 & \\
\hline & $\begin{array}{l}\text { Jumlah } \\
\text { Sampel }\end{array}$ & $\underset{(\mathrm{dB})}{(f s)}$ & $\begin{array}{l}\text { Frekuensi } \\
\text { fundamental } \\
\text { (dB) }\end{array}$ & $\begin{array}{c}(\mathrm{s}+f) \\
(\mathrm{dB})\end{array}$ \\
\hline \multirow{4}{*}{$\begin{array}{l}\text { Nilai } \\
\text { amplitudo } \\
\text { (dB) }\end{array}$} & Sampel 1 & -12.23 & 10,16 & $-21,62$ \\
\hline & Sampel 2 & $-12,2$ & 10,12 & $-21,55$ \\
\hline & Sampel 3 & $-12,02$ & 10,2 & $-21,6$ \\
\hline & Sampel 4 & $-11,66$ & 9,392 & $-24,72$ \\
\hline \multicolumn{2}{|c|}{ Rata-Rata } & $-12,02$ & 9,968 & $-22,37$ \\
\hline & $\begin{array}{l}\text { Jumlah } \\
\text { Sampel }\end{array}$ & $\begin{array}{c}(s+f) \\
(\mathrm{d} B \mathrm{~B})\end{array}$ & $\begin{array}{c}\text { Frelzuensi } \\
\text { fundamental } \\
\text { (dB) }\end{array}$ & $\begin{array}{c}(\mathrm{s}+f) \\
(\mathrm{dB})\end{array}$ \\
\hline \multirow{4}{*}{$\begin{array}{c}\text { Nalai } \\
\text { amplitudo } \\
\text { (dB) }\end{array}$} & Sampel 1 & $-12,96$ & 7,705 & $-23,96$ \\
\hline & Sampel 2 & $-12,49$ & 9,173 & $-24,5$ \\
\hline & Sampel 3 & $-12,75$ & 7,831 & $-22,65$ \\
\hline & Sampel 4 & $-13,03$ & 7,707 & $-24,03$ \\
\hline \multicolumn{2}{|c|}{ Rata - Rata } & $-12,655$ & 8,16575 & $-23,365$ \\
\hline
\end{tabular}

Figure 5. Hasil Rata-Rata Pembebanan 0\% sampel 1 sampai 4 di kondisi motor induksi normal

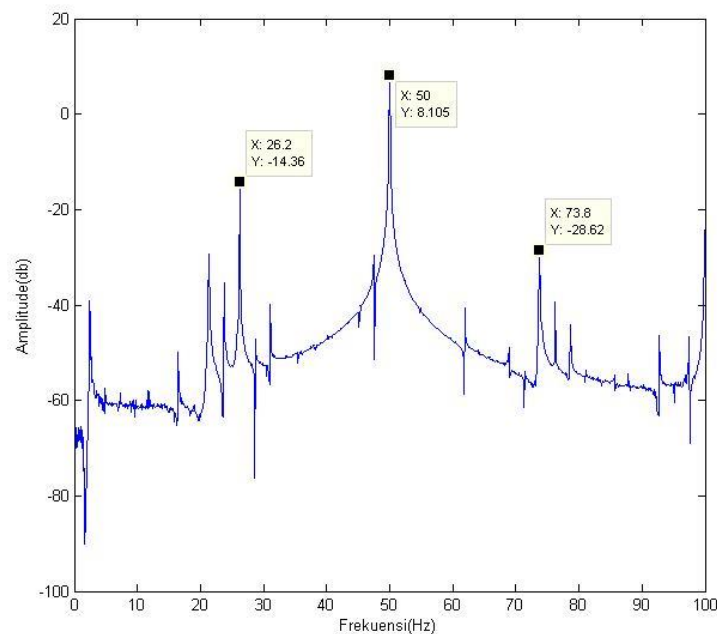

Figure 6. Kondiai Normal 


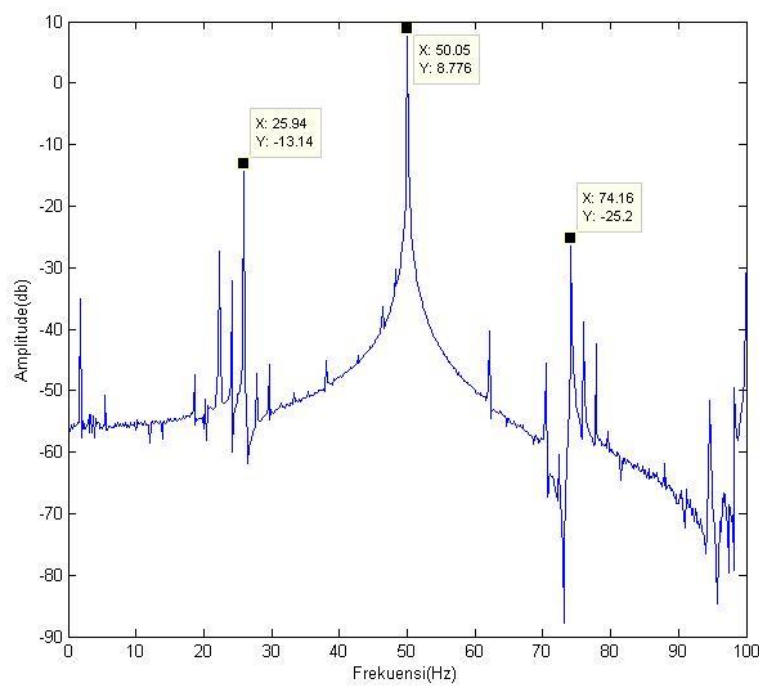

Figure 7. Kondisi Gangguan Hubung Singkat 1-3

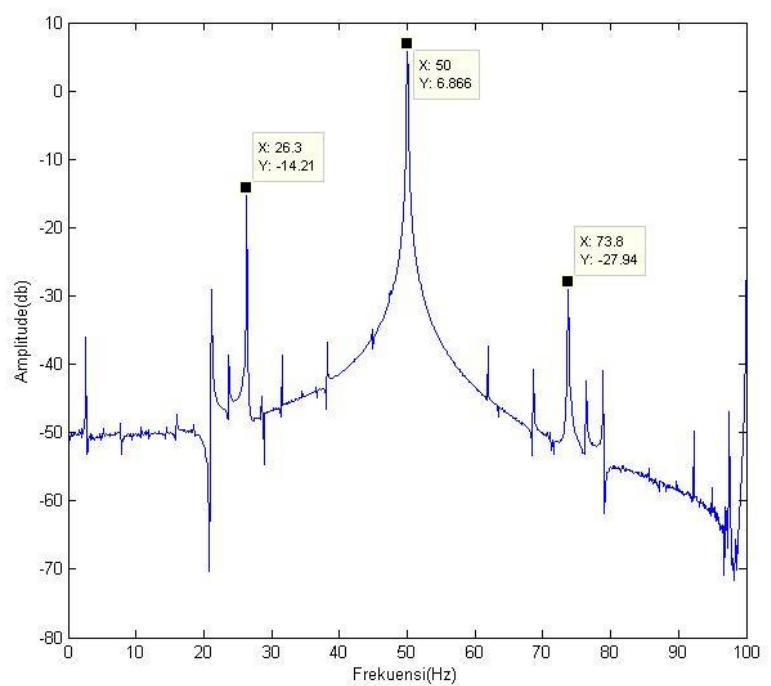

Figure 8. Gangguan Hubung Singkat 2-10 


\begin{tabular}{|c|c|c|c|c|}
\hline \multicolumn{5}{|c|}{ Beban 7546 Normal } \\
\hline & $\begin{array}{l}\text { Jumlah } \\
\text { Sampel }\end{array}$ & $\begin{array}{c}(f s-f t) \\
(\mathrm{dB})\end{array}$ & $\begin{array}{l}\text { Frekueusi } \\
\text { Fundamental } \\
\text { (dB) }\end{array}$ & $\begin{array}{c}(\mathrm{fS}+f \mathrm{f}) \\
(\mathrm{dB})\end{array}$ \\
\hline \multirow{4}{*}{$\begin{array}{c}\text { Nilai } \\
\text { amplitudo } \\
\text { (dB) }\end{array}$} & Sampel 1 & $-14,36$ & 8,105 & $-28,62$ \\
\hline & Sampel 2 & $-14,57$ & 8,035 & $-26,03$ \\
\hline & Sampel 3 & $-14,56$ & 8,43 & $-26,39$ \\
\hline & Sampel 4 & $-14,36$ & 8,105 & $-28,62$ \\
\hline \multicolumn{2}{|c|}{ Rata - Rata } & $-14,4625$ & 8,16875 & $-27,415$ \\
\hline & & & gleat 1 & \\
\hline & $\begin{array}{l}\text { Jumlah } \\
\text { Sampel }\end{array}$ & 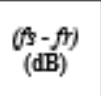 & $\begin{array}{l}\text { Frekueusi } \\
\text { fundamental } \\
\text { (dB) }\end{array}$ & $\begin{array}{c}(A s+f t) \\
(d \mathrm{~dB})\end{array}$ \\
\hline \multirow{4}{*}{$\begin{array}{c}\text { Nilai } \\
\text { amplitudo } \\
\text { (dB) }\end{array}$} & Sampel 1 & $-13,14$ & 8,776 & $-25,2$ \\
\hline & Sampel 2 & $-14,66$ & 8,35 & $-25,81$ \\
\hline & Sampel 3 & $-14,99$ & 7,585 & -27 \\
\hline & Sampel 4 & $-15,07$ & 7,627 & $-26,26$ \\
\hline \multicolumn{2}{|c|}{ Rata - Rata } & $-14,465$ & 8,0845 & $-26,0675$ \\
\hline & & agy & lung Singlat 2 . & \\
\hline & $\begin{array}{l}\text { Jumlah } \\
\text { Sampel }\end{array}$ & $\begin{array}{c}\left(\begin{array}{c}s \\
(\mathrm{~dB})\end{array}\right) \\
(\mathrm{dB})\end{array}$ & $\begin{array}{c}\begin{array}{c}\text { Frekueusi } \\
\text { fundamental } \\
\text { (dB) }\end{array} \\
\end{array}$ & $\begin{array}{c}(f+f f) \\
(\mathrm{dBB})\end{array}$ \\
\hline \multirow{4}{*}{$\begin{array}{c}\text { Nilai } \\
\text { amplitudo } \\
\text { (dB) }\end{array}$} & Sampel 1 & $-14,21$ & 6,866 & $-27,94$ \\
\hline & Sampel 2 & $-14,06$ & 6,973 & $-26,66$ \\
\hline & Sampel 3 & $-14,17$ & 7,664 & $-29,1$ \\
\hline & Sampel 4 & $-14,16$ & 7,433 & $-28,37$ \\
\hline \multicolumn{2}{|c|}{ Rata - Rata } & $-14,15$ & 7,234 & $-28,0175$ \\
\hline
\end{tabular}

Figure 9. Hasil Rata-Rata Pembebanan 75\% Sampel 1 Sampai 4 Di Kondisi Motor Induksi Normal

\begin{tabular}{|c|r|r|r|r|r|}
\hline \multirow{2}{*}{ Beban } & \multicolumn{1}{|c|}{$\begin{array}{c}\text { Gangguan hubung } \\
\text { singkat 1-3 }\end{array}$} & \multicolumn{2}{c|}{$\begin{array}{c}\text { Gangguan hubung } \\
\text { singkat 2-10 }\end{array}$} & \multirow{2}{*}{ Presentase } \\
\cline { 2 - 5 } & $(f s-f r)(d B)$ & $(f s+f r)(d B)$ & $(f s-f r)(d B)$ & $(f s+f r)(d B)$ & \\
\hline $0 \%$ & 1,005 & 1,3575 & 0,4375 & 0,3625 & $100 \%$ \\
\hline $25 \%$ & $-0,2675$ & $-0,17$ & 0,0725 & 1,2 & $50 \%$ \\
\hline $50 \%$ & $-0,1575$ & $-0,195$ & 0,21 & 0,4325 & $50 \%$ \\
\hline $75 \%$ & $-0,0025$ & 1,3475 & 0,3125 & $-0,6025$ & $25 \%$ \\
\hline $100 \%$ & 0,105 & $-0,56$ & $-0,4425$ & 0,63 & $25 \%$ \\
\hline \multicolumn{5}{|c|}{ Rata-rata } \\
\hline
\end{tabular}

Figure 10. Diatas Merupakan Hasil Analisa Presentase Keberhasilan 